\title{
Faktor Caregiver dan Kekambuhan Klien Skizofrenia
}

\author{
Laeli Farkhah ${ }^{1}$, Suryani ${ }^{2}$, Taty Hernawati ${ }^{2}$ \\ ${ }^{1}$ RSKJ H. Mustajab, Purbalingga, ${ }^{2}$ Fakultas Keperawatan, Universitas Padjadjaran \\ Email: laelifarkhah@gmail.com
}

\begin{abstract}
Abstrak
Caregiver merupakan orang yang bertanggung jawab memberikan perawatan secara langsung dalam segala situasi, baik saat pasien kambuh atau tidak kambuh. Beberapa faktor caregiver yang berhubungan dengan kekambuhan pasien skizofrenia adalah dukungan keluarga, pengetahuan tentang pengobatan skizofrenia, peristiwa kehidupan yang penuh stres, dan kualitas hidup caregiver. Penelitian ini bertujuan untuk menganalisis faktor caregiver yang berhubungan dengan kekambuhan pasien skizofrenia. Penelitian ini merupakan penelitian deskriptif analitik dengan rancangan crosssectional. Pengambilan sampel dengan consecutive sampling sebanyak 30 orang. Data dikumpulkan menggunakan kuesioner. Analisis data menggunakan uji korelasi Pearson Product Moment untuk melihat hubungan antara dua variabel dan uji regresi logistik untuk menentukan faktor yang dominan berhubungan dengan frekuensi kekambuhan pasien skizofrenia. Hasil penelitian menunjukkan semua variabel memiliki hubungan dengan frekuensi kekambuhan pasien skizofrenia. Variabel dukungan keluarga memiliki hubungan yang kuat dengan arah hubungan yang negatif $(\mathrm{r}=-0,630)$. Variabel pengetahuan keluarga memiliki hubungan yang sedang dengan arah hubungan yang negatif $(\mathrm{r}=-0,820)$. Variabel kualitas hidup memiliki hubungan yang sangat kuat dengan arah hubungan yang negatif $(\mathrm{r}=-0,560)$. Variabel peristiwa hidup penuh stres memiliki hubungan yang sedang dengan arah hubungan yang positif $(\mathrm{r}=0,447)$. Hasil analisis regresi logistik menunjukkan bahwa faktor caregiver yang paling dominan berhubungan dengan dengan kekambuhan adalah kualitas hidup dengan nilai $r=-0,560$ dan koefisien determinannya (r2) yaitu 0,768 yang memiliki kekuatan hubungan (OR) 25,093. Dari penelitian ini dapat disimpulkan bahwa kualitas hidup caregiver merupakan faktor yang paling dominan terhadap kekambuhan. Penelitian ini merekomendasikan agar perawat berperan aktif dalam meningkatkan kualitas hidup caregiver dan pentingnya caregiver support group dalam rangka meningkatkan kualitas hidup caregiver.
\end{abstract}

Kata kunci: Caregiver, kekambuham, skizofrenia.

\section{Caregivers Factors and Relaps in Schizophrenia}

\begin{abstract}
Caregiver is the person who responsible for providing direct care in all situations, both when patients relapse or recurrence. The caregiver's factors associated with the relapse of patients are family support, knowledge about the treatment of schizophrenia, stressful life events, and quality of life of the caregiver. This study aimed to analyze caregiver's factors associated with the relapse of patients with schizophrenia. This research is descriptive analytic with cross sectional design. Sampling using consecutive sampling. Number of samples in this study were 30. Data were collected using a questionnaire.Data were analised by Pearson Product Moment Correlation test to look at the relationship between two variables and logistic regression to identify the dominant factor related to the relapse of patients with schizophrenia. The results showed all variables have a relationship with the frequency of relapse. The family support has a strong relationship with the direction of a negative relationship ( $\mathrm{r}$ $=-0.630$ ). Family knowledge about schizophrenia had relationships with the direction of a negative relationship $(\mathrm{r}=-0.820)$. Variable quality of life has a very strong relationship with the direction of the negative correlation $(\mathrm{r}=-0.560)$. Variable stressful life events had a relationship that was the direction of a positive relationship ( $\mathrm{r}$ $=0.447)$. The results of logistic regression analysis showed that the most dominant factor of the relapse was quality of life with a value of $r=-0.56$ and determinant coefficient (r2) is 0.768 which has the strength of the relationship (OR) 25.093. From this research it can be concluded that the quality of life of caregivers is the most dominant factor among the three factors associated with patients relapse. The study recommends nurses must play an active role to improve the quality of life of caregivers and to implement caregiver support group.
\end{abstract}

Keywords: Caregiver, relapse, schizophrenia. 


\section{Pendahuluan}

Fenomena skizofrenia di Indonesia setiap tahunnya selalu mengalami peningkatan. Menurut World Health Organization, pada tahun 2014 angka penderita skizofrenia di seluruh dunia lebih dari 21 juta jiwa (WHO, 2014). Selain itu, prevalensi skizofrenia (gangguan jiwa berat) sebesar 1,7 per mil secara nasional. Berdasarkan salah satu penelitian baru-baru ini prevalensi kekambuhan pada penderita skizofrenia berada dalam rentang $50-92 \%$ secara global (Weret \& Mukherjee, 2014). Terdapat lima pihak yang menyebabkan penderita skizofrenia kambuh antara lain: pasien sendiri, dokter atau petugas kesehatan, penanggung jawab pasien, keluarga, dan lingkungan sekitar (Sullinger,1988 dalam Keliat, 2006). Keluarga, terutama yang menjadi caregiver memiliki tanggung jawab penting dalam proses perawatan di rumah sakit, persiapan pulang, dan perawatan di rumah (continum of care). Peran keluarga sebagai caregiver sangat penting dalam menangani dan mencegah gejala kekambuhan karena mereka bertanggung jawab memberikan perawatan secara langsung kepada pasien skizofrenia dalam segala situasi (continuum of care).

Buckley (2006) mengungkapkan bahwa kekambuhan pasien skizofrenia dapat berkurang signifikan dari $65 \%$ menjadi $25 \%$ jika mendapat perawatatan yang maksimal dari keluarga selama berada di rumah. Sebaliknya bila tidak mendapat perawatan yang tepat, mereka akan cenderung mudah kambuh. Daya dukung keluarga yang buruk berpengaruh pada pasien skizofrenia sehingga memiliki peluang 6 kali lipat mengalami kekambuhan dibandingkan keluarga yang memiliki dukungan baik (Pratama, Syahrial, \& Isak, 2015).

Anggota keluarga yang berperan sebagai caregiver, tentunya mempunyai peran yang sangat sentral agar dapat merawat pasien skizofrenia di rumah dengan baik. Menurut beberapa penelitian ditemukan beberapa faktor caregiver yang berhubungan dengan kekambuhan pasien skizofrenia antara lain faktor pengetahuan dan dukungan (support) (Felicia, 2012), kualitas hidup (Rafiyah, 2011), dan peristiwa hidup yang penuh stress selama merawat pasien (Ingkikiriwang,
2010). Berdasarkan penelusuran literatur belum ditemukan faktor caregiver yang paling dominan terhadap kekambuhan pasien skizofrenia. Berdasarkan latar belakang di atas, maka diperlukan penelitian yang berhubungan dengan faktor-faktor caregiver antara lain: dukungan keluarga, pengetahuan tentang skizofrenia, peristiwa kehidupan yang penuh stres, dan kualitas hidup yang berhubungan dengan kekambuhan skizofrenia

\section{Metode Penelitian}

Penelitian ini merupakan penelitian deskriptif analitik dengan rancangan crosssectional. Pengambilan sampel menggunakan teknik non probability sampling yaitu dengan consecutive sampling, dengan kriteria inklusi: keluarga yang menjadi caregiver klien kambuhan skizofrenia yang dirawat di RSJ, mampu memahami kuesioner, dapat membaca dan menulis, dan minimal berinteraksi satu kali sehari dengan klien. Jumlah sampel pada penelitian ini sebanyak 30 responden. Pengukuran kekambuhan menggunakan skala Guttman yang merupakan skala yang menginginkan tipe jawaban tegas dilihat dari rekam medis. Pada penelitian ini, kambuh diartikan apabila pasien menunjukkan gejala yang sama dengan sebelumnya dan tidak kambuh jika pasien tidak menunjukkan gejala dalam dalam rentang waktu 1 tahun terakhir. Skala Guttman dibuat dalam bentuk daftar checklist.

Di samping itu, terdapat empat instrumen dalam penelitian ini, yaitu: instrumen dukungan keluarga yang merupakan hasil modifikasi dari Friedman (2010) dan WHO (2008) untuk mengukur dukungan keluarga yang mencakup: dukungan informasional, dukungan penilaian, dukungan instrumental, dan dukungan emosional terhadap pasien skizofrenia yang sudah divalidasi menggunakan rumus Person Product Moment dengan nilai koefisien korelasi 0,79 dan juga uji reliabilitas menggunakan rumus Spearman Brown dengan koefisien reliabilitas internal seluruh item sebesar 0,8 . Instrumen pengetahuan keluarga menggunakan kuesioner baku yaitu "Knowledge Questionnaire on Home Care of Schizophreincs (KQHS)". Instrumen 
Laeli Farkhah : Faktor Caregiver dan Kekambuhan Klien Skizofrenia

kualitas hidup caregiver menggunakan alat ukur (WHOQOL-BREF), dan instrumen tentang peristiwa kehidupan yang penuh stres, menggunakan Caregiver SelfAssessment Questionare (American Medical Association). Data dikumpulkan menggunakan 4 kuesioner tersebut. Analisis data terdiri dari uji univariat, bivariat, dan multivariat. Uji bivariat untuk melihat hubungan antara dua variabel menggunakan uji korelasi Pearson Product Moment. Uji multivariat menggunakann uji regresi logistik untuk menentukan faktor yang dominan berhubungan dengan frekuensi kekambuhan pasien skizofrenia.

\section{Hasil Penelitian}

Proses penelitian ini telah dilaksanakan selama enam bulan (Juni-November 2016) dan proses pengumpulan data telah dilakukan selama satu bulan (tanggal 1-30 September 2016). Dalam kurun waktu tersebut, diperoleh subjek penelitian sebanyak 30 responden dan semua berpartisipasi hingga selesai proses penelitian. Setelah dilakukan proses analisis data dengan uji statistik, penulis menguraikan hasil penelitian berdasarkan urutan tujuan penelitian yang telah penulis rencanakan. Berikut adalah pemaparan hasil penelitian yang disajikan dalam tiga jenis analisis, yaitu univariat, bivariat, dan multivariat.

Karekteristik responden seperti usia, hubungan dengan pasien, tingkat pendidikan, jenis kelamin, dan pendapatan dijelaskan pada tabel 1. Usia responden terbanyak

Tabel 1 Distribusi Frekuensi Karekteristik Responden berdasarkan Usia, Hubungan dengan Pasien, Jenis Kelamin, Tingkat Pendidikan, dan Pendapatan $(\mathbf{N}=\mathbf{3 0})$

\begin{tabular}{|c|c|c|c|}
\hline & Karekteristik Responden & Frekuensi (N) & Persentase (\%) \\
\hline \multicolumn{4}{|c|}{ Usia } \\
\hline 1) & $17-25$ tahun & 4 & $13 \%$ \\
\hline 2) & 26-35 tahun & 4 & $13 \%$ \\
\hline 3) & $36-45$ tahun & 12 & $40 \%$ \\
\hline 4) & 46-55 tahun & 4 & $13 \%$ \\
\hline 5) & $55-65$ tahun & 4 & $13 \%$ \\
\hline 6) & $>65$ tahun & 2 & $8 \%$ \\
\hline \multicolumn{4}{|c|}{ Hubungan dengan Pasien } \\
\hline 1) & Ibu Kandung & 12 & $40 \%$ \\
\hline 2) & Ayah Kandung & 6 & $20 \%$ \\
\hline 3) & Saudara & 8 & $27 \%$ \\
\hline 4) & Kerabat & 4 & $13 \%$ \\
\hline \multicolumn{4}{|c|}{ Jenis Kelamin } \\
\hline 1) & Laki-laki & 8 & $27 \%$ \\
\hline 2) & Perempuan & 22 & $73 \%$ \\
\hline \multicolumn{4}{|c|}{ Tingkat Pendidikan } \\
\hline 1) & SD & 8 & $27 \%$ \\
\hline 2) & SMP & 14 & $47 \%$ \\
\hline 3) & SMA & 6 & $20 \%$ \\
\hline 4) & Perguruan Tinggi & 2 & $6 \%$ \\
\hline \multicolumn{4}{|c|}{ Pendapatan } \\
\hline 1) & $<\operatorname{Rp} 1.500 .000$ & 18 & $60 \%$ \\
\hline 2) & Rp 1.500.000-Rp 2.500.000 & 8 & $26 \%$ \\
\hline 3) & Rp 2.500.000-Rp 3.500.000 & 2 & $7 \%$ \\
\hline 4) & $>\operatorname{Rp} 3.500 .000$ & 2 & $7 \%$ \\
\hline
\end{tabular}


adalah 36-45 tahun (40\%), hubungan dengan pasien terbanyak adalah ibu kandung (40\%), jenis kelamin perempuan $(73 \%)$, pendidikan SMP (47\%), dan pendapatan dibawah 1,5 juta $(60 \%)$.

Hasil analisis univariat dijelaskan di tabel 2. Tampak pada tabel bahwa dukungan keluarga paling banyak adalah dalam katagori rendah $(43 \%)$, pengetahuan paling banyak dalam katagori buruk (47\%), kualitas hidup rendah $(40 \%)$, dan peristiwa hidup yang penuh stres $(67 \%)$. Kekambuhan pasien yang paling banyak adalah 3 kali setahun, bahkan ada yang 8 kali dalam setahun.

Hasil analisis bivariat dijelaskan pada tabel 4. Hubungan dukungan keluarga dengan frekuensi kekambuhan skizofrenia menunjukkan hubungan yang kuat dan

Tabel 2 Distribusi Frekuensi Dukungan Keluarga, Pengetahuan Keluarga tentang Pengobatan Skizofrenia, Tingkat Peristiwa Stres Keluarga, dan Kualitas Hidup Keluarga sebagai Caregiver $(\mathbf{N}=\mathbf{3 0})$

\begin{tabular}{lcc}
\hline \multicolumn{1}{c}{ Variabel } & Frekuensi (N) & Persentase (\%) \\
\hline Dukungan Keluarga (X1) & $\mathbf{1 3}$ & 43 \\
Rendah & $\mathbf{6}$ & 20 \\
Sedang & $\mathbf{1 1}$ & 37 \\
Tinggi & & \\
Pengetahuan Keluarga tentang & $\mathbf{6}$ & 20 \\
Skizofrenia (X2) & $\mathbf{1 4}$ & 47 \\
Sangat Buruk & $\mathbf{8}$ & 27 \\
Buruk & - & - \\
Sedang & $\mathbf{2}$ & 6 \\
Baik & & \\
Sangat Baik & $\mathbf{1 2}$ & 40 \\
Kualitas Hidup Keluarga (X3) & $\mathbf{1 1}$ & 37 \\
Rendah & $\mathbf{7}$ & 23 \\
Sedang & & \\
Tinggi & 10 & 33 \\
Peristiwa hidup yang penuh & 20 & 67 \\
stress (X4) & & \\
Tidak & & \\
Ya & & \\
\hline
\end{tabular}

Tabel 3 Distribusi Frekuensi Kekambuhan Pasien Skizofrenia dalam Satu Tahun Terakhir di RSKJ H. Mustajab (N = 30)

\begin{tabular}{lcc}
\hline \multicolumn{1}{c}{ Kekambuhan } & Frekuensi (N) & Persentase (\%) \\
\hline $\begin{array}{l}\text { Frekuensi Kekambuhan dalam } \\
\text { 1 tahun }\end{array}$ & & \\
1 kali & 4 & 13 \\
2 kali & 5 & 17 \\
3 kali & 7 & 23 \\
4 kali & 5 & 17 \\
5 kali & 3 & 10 \\
7 kali & 3 & 10 \\
8 kali & 3 & 10 \\
\hline
\end{tabular}


Laeli Farkhah : Faktor Caregiver dan Kekambuhan Klien Skizofrenia

Tabel 4 Hubungan Dukungan Keluarga dengan Frekuensi Kekambuhan Pasien Skizofrenia di RSKJ H. Mustajab Tahun $2016(\mathbf{N}=30)$

\begin{tabular}{lcccc}
\hline \multicolumn{1}{c}{ Variabel } & P value & $\mathbf{R}$ & r2 & N \\
\hline Dukungan Keluarga & 0,000 & $-0,630$ & 0,741 & 30 \\
$\begin{array}{l}\text { Pengetahuan Keluarga mengenai Pengobatan } \\
\text { Skizofrenia }\end{array}$ & 0,000 & $-0,82$ & 0,665 & 30 \\
Kualitas Hidup Keluarga & 0,000 & $-0,56$ & 0,768 & 30 \\
Peristiwa Hidup yang Penuh Stres & 0,000 & 0,447 & 0,13 & 30 \\
\hline
\end{tabular}

Tabel 5 Hasil Analisis Multivariat Regresi Logistik

\begin{tabular}{|c|c|c|c|c|c|c|c|c|c|}
\hline & & B & S.E. & Wald & df & Sig. & $\operatorname{Exp}(\mathrm{B})$ & $\begin{array}{r}95.0 \% \\
\text { C.I.for } \\
\text { EXP(B) }\end{array}$ & \\
\hline & & & & & & & & Lower & Upper \\
\hline \multirow{5}{*}{$\begin{array}{l}\text { Step } \\
1(a)\end{array}$} & Dukungan keluarga & $-1,117$ & 0,682 & 2,679 & 1 & 0,102 & 4,327 & 0,086 & 1,247 \\
\hline & $\begin{array}{l}\text { Pengetahuan } \\
\text { keluarga }\end{array}$ & 2,538 & 1,518 & 2,96 & 1 & 0,094 & 12,653 & 0,646 & 247,752 \\
\hline & Tingkat stres & 0,567 & 0,705 & 0,645 & 1 & 0,422 & 11,762 & 0,442 & 7,021 \\
\hline & Kualitas hidup & 2,377 & 0,928 & 6,564 & 1 & 0,01 & 25,093 & 0,015 & 0,572 \\
\hline & Constant & 2,309 & 3,014 & 0,587 & 1 & 0,444 & 10,067 & & \\
\hline
\end{tabular}

a Variable(s) entered on step 1: Dukungan_keluarga, Pengetahuan_keluarga, Tingkat_stress, Kualitas_hidup

memiliki arah hubungan negatif (nilai $\mathrm{r}=$ $-0,630)$. Hubungan pengetahuan keluarga sebagai caregiver dengan frekuensi kekambuhan skizofrenia menunjukkan hubungan yang sedang dan memiliki arah hubungan negatif (nilai $r=-0,82$ ). Hubungan kualitas hidup keluarga sebagai caregiver dengan frekuensi kekambuhan skizofrenia menunjukkan hubungan yang sangat kuat dan memiliki arah hubungan negatif (nilai $r=-0,56)$. Hubungan peristiwa hidup yang penuh stres dengan frekuensi kekambuhan skizofrenia menunjukkan hubungan yang sedang dan memiliki arah hubungan positif (nilai $\mathrm{r}=0,447$ ).

Hasil analisis multivariat dapat dilihat pada tabel 5. Tampak bahwa kekuatan hubungan dari yang terkecil menuju terbesar adalah dukungan keluarga $(\mathrm{OR}=4,327)$, tingkat stress keluarga $(\mathrm{OR}=11,762)$, pengetahuan keluarga $(\mathrm{OR}=12,653)$, dan kualitas hidup keluarga sebagai caregiver $(\mathrm{OR}=25,093)$.

\section{Pembahasan}

Frekuensi kekambuhan pasien skizofrenia ditentukan oleh berbagai faktor, baik itu dari pihak caregiver yang merawatnya maupun pasien itu sendiri. Menurut Buckley (2006), kekambuhan pasien skizofrenia dapat berkurang signifikan dari $65 \%$ menjadi $25 \%$ jika mendapat perawatatan yang maksimal dari keluarga selama berada di rumah. Faktorfaktor keluarga sebagai caregiver meliputi dukungan keluarga, pengetahuan keluarga tentang pengobatan skizofrenia, peristiwa kehidupan yang penuh stres, dan kualitas hidup keluarga sebagai caregiver.

Dukungan keluarga merupakan salah satu aspek yang penting dalam mencegah kekambuhan pasien skizofrenia. Hasil analisis pada penelitian ini menunjukkan bahwa sebagian besar caregiver memberikan dukungan rendah (43\%). Menurut Christy (2011) bahwa frekuensi kekambuhan pasien tinggi pada saat dukungan yang diberikan caregiver mengalami penurunan. Penelitian lain oleh Hemels dan Schreiner (2013) juga menemukan rendahnya faktor dukungan ekonomi dan adanya konflik peran perawatan yang dijalani di rumah menyebabkan tingginya frekuensi kekambuhan. Selain itu, sebagian besar responden memiliki 
penghasilan yang sangat kurang sehingga menyebabkan caregiver tidak maksimal dalam memberikan dukungan materi kepada pasien skizofrenia.

Dukungan keluarga yang rendah berhubungan dengan rendahnya pendapatan keluarga. Pendapatan rata-rata keluarga perbulan kurang dari 1 juta. Pendapatan ini di bawah batas UMR. Pendapatan tersebut diasumsikan sebagai pendapatan yang biasa diperoleh jika bekerja.Kondisi pasien skizofrenia yang harus dirawat di rumah menjadikan caregiver tidak dapat bekerja seperti biasanya. Apalagi jika caregiver bekerja harian, mereka kehilangan pendapatannya selama merawat penderita skizofrenia. Menurut Awad dan Voruganti (2010), aspek ekonomi sangat memengaruhi dukungan caregiver untuk konsisten dalam memberikan perawatan kepada pasien skizofrenia di rumah.

Ditambahkan pula oleh Chan (2015) mengenai konsep yang mendukung bahwa frekuensi kekambuhan yang dialami pasien skziofrenia bisa terlihat dari dukungan perasaan (afeksi), baik verbal maupun nonverbal. Kebutuhan terhadap kedekatan merupakan kebutuhan yang sangat penting agar caregiver bisa tetap dekat dengan penderita skizofrenia baik secara fisik maupun emosional (Mubarak, 2013). Berdasarkan hasil penelitian Epstein-Lubow (2010), pasien skziofrenia mengalami penurunan frekuensi kekambuhannya setelah mendapatkan dukungan moral yang diwujudkan dalam keterlibatan caregiver dalam setiap aktivitas pasien skziofrenia.

Hasil uji bivariat antara faktor dukungan keluarga sebagai caregiver dengan frekuensi kekambuhan pasien skizofrenia menunjukkan hubungan yang kuat dan memiliki arah hubungan negatif, artinya semakin bertambah dukungan yang diberikan keluarga maka semakin berkurang frekuensi kekambuhan pasien skizofrenia. Intervensi yang dapat dilakukan untuk meningkatkan dukungan keluarga sebagai caregiver pasien skizofrenia adalah dengan adanya peran aktif dari petugas kesehatan terutama perawat jiwa yang bertugas di bangsal rawat inap untuk memantau data kunjungan keluarga pasien dan aktif menghubungi keluarga pasien jika jarang menengok pasien di rumah sakit. Di samping itu, apabila keluarga pasien tidak memiliki alat komunikasi maka sebaiknya meminta nomor telpon tetangga terdekat dan rutin melakukan kunjungan rumah untuk memotivasi keluarga. Selain itu, pada caregiver yang menunggu pasien, perawat jiwa dapat melibatkan keluarga secara langsung memberikan dukungan pemberi informasi, pemberi umpan balik, dukungan kebutuhan hidup dan dukungan perasaan kepada pasien.

Sejalan dengan pendapat Porsdal et al. (2010) bahwa perawat jiwa berperan sebagai anggota tim kolaborasi dan multidisiplin. Menurut Fisher (2011), perawat berperan sebagai media pemberi layanan terapeutik yang penting, dan mendorong untuk memberdayakan pasien dan keluarganya (dukungan keluarga), serta menanamkan harapan pada keluarga dan pasien.

Selain dukungan keluarga, faktor pengetahuan keluarga juga merupakan salah satu aspek yang penting dalam mencegah kekambuhan pasien skizofrenia. Hasil analisis pada penelitian ini menunjukkan bahwa hampir setengah dari jumlah responden ternyata memiliki tingkat pengetahuan yang rendah mengenai pengobatan skizofrenia (47\%). Sejalan dengan Siregar (2005), yang mengatakan bahwa apabila keluarga pasien mempunyai pengetahuan yang buruk atau pemahaman yang rendah tentang pengobatan skizofrenia, maka frekuensi kekambuhan pasien akan bertambah. Di samping itu, meskipun tidak memengaruhi kekambuhan pasien skizofrenia secara langsung, tingkat pendidikan rupanya berhubungan dengan rendahnya tingkat pengetahuan responden mengenai pengobatan skizofrenia. Menurut Chorwe-Sungani, Namelo, Chiona, dan Nyirongo (2015), semakin tinggi tingkat pendidikan formal seseorang maka dapat dengan mudah menerima informasi dan melakukan pemanfaatan terhadap pelayanan kesehatan yang tersedia untuk meningkatkan pengetahuannya tentang skizofrenia. Pada penelitian ini sebagian besar caregiver memiliki latar belakang SMP dengan jumlah 14 responden (47\%). Mereka masih sulit memahami istilah-istilah dalam perawatan dan pengobaran pasien, sehingga hanya bisa pasrah dan mengandalkan tenaga kesehatan saja untuk merawat pasien skizofrenia. 
Hal ini diperkuat oleh penjelasan keluarga pasien yang pada umumnya mengatakan bahwa dirinya tidak memperoleh informasi tentang penyakit dan pengobatan skizofrenia secara menyeluruh. Di samping itu, akses informasi yang cukup sulit karena sebagian besar keluarga pasien berdomisili di daerah pedesaan yang belum terfasilitasi internet dan jauh dari Puskesmas. Selain itu, pada saat keluarga membawa pasien ke pusat pelayanan kesehatan dan mendapat perawatan pada saat persiapan pasien pulang, keluarga hanya mendapat informasi tentang pemberian obat dan waktu kontrol pasien. Penyuluhan oleh perawat di ruang perawatan terhadap keluarga pasien juga masih jarang dilakukan. Keluarga pasien pada umumnya mengatakan perawat dari Puskesmas terdekat jarang melakukan penyuluhan maupun kunjungan rumah.

Pada hasil uji bivariat ditemukan hubungan pengetahuan keluarga sebagai caregiver dengan frekuensi kekambuhan skizofrenia mempunyai hubungan yang sedang dan memiliki arah hubungan negatif artinya semakin baik pengetahuan keluarga mengenai pengobatan skizofrenia, maka semakin berkurang frekuensi kekambuhan pasien skizofrenia. Hasil penelitian ini sejalan dengan penjelasan Felicia (2012) yang menyimpulkan bahwa kekambuhan pasien skizofrenia dipengaruhi oleh pengetahuan keluarga.Semakin baik pengetahuan keluarga mengenai pengobatan skizofrenia, maka semakin berkurang frekuensi kekambuhan pasien skizofrenia.

Selanjutnya, peristiwa kehidupan yang penuh stres yang dialami caregiver merupakan salah satu aspek yang penting dalam mencegah kekambuhan pasien skizofrenia. Hasil analisis pada penelitian ini menunjukkan bahwa lebih dari setengah responden mengalami peristiwa kehidupan yang penuh stres yaitu sebesar $67 \%$. Hasil penelitian ini sejalan dengan pendapat Alsherif dan Elrahman (2013), bahwa kekambuhan pasien skizofrenia meningkat apabila keluarga memperlihatkan suasana hati yang kurang baik di rumahnya. Dan juga sesuai dengan penjelasan Sachit dan AlJubbori (2013), bahwa emosi keluarga yang tinggi karena situasi penuh stres yang dialami keluarga sebagai caregiver, menimbulkan efek yang kuat dan memicu kambuh pasien skizofrenia.

Hasil uji bivariat antara peristiwa kehidupan yang penuh stres dengan frekuensi kekambuhan menunjukkan hubungan yang sedang dan memiliki arah hubungan positif, artinya terjadinya peristiwa hidup yang penuh stres akan menyebabkan meningkatnya frekuensi kekambuhan pasien skizofrenia. Sariah (2014) menyimpulkan bahwa salah satu penyebab kambuhnya penyakit skizofrenia disebabkan oleh peristiwa kehidupan keluarga yang penuh dengan tekanan (stres).

Di samping itu, pada umumnya responden mengatakan belum memiliki pengalaman merawat pasien skizofrenia yang terlihat dari caregiver mendapatkan support dari keluarga (ibu atau suami) yang menemani selama pasien menjalani perawatan di rumah sakit. Selain itu, caregiver pasien skizofrenia juga mendapatkan dukungan dari caregiver lainnya di ruang perawatan, sehingga mereka mendapatkan cerita pengalamannya, motivasi maupun informasi terkait peristiwaperistiwa yang dijalani selama hidup bersama penderita skizofrenia. Sejalan dengan hasil penelitian Birley dan Wing (2007), orang tua yang mempunyai pengalaman merawat anak menentukan bagaimana kondisi mental seorang anak di masa mendatang.

Terakhir, faktor kualitas hidup sebagai caregiver. Kualitas hidup keluarga sebagai caregiver merupakan salah satu aspek yang penting dalam mencegah kekambuhan pasien skizofrenia. Hasil analisis pada penelitian ini menunjukkan bahwa sebanyak $40 \%$ caregiver memiliki kualitas hidup yang rendah. Rafiah (2011) menemukan bahwa rendahnya kualitas hidup caregiver berdampak terhadap kualitas caregiver dalam merawat pasien skizofrenia. Pada penelitian ini, umumnya responden mengatakan kesulitan untuk membagi waktu untuk bekerja, menyelesaikan pekerjaan rumah tangga, dan merawat pasien. Hal ini sejalan dengan pendapat Espina (2003), menjelaskan permasalahan stres dan penurunan kualitas hidup keluarga sebagai caregiver berkaitan dengan pergeseran pekerjaan, tugas rumah tangga, dan merawat pasien.

Hasil penelitian Gutierrez (2006), menemukan bahwa beban ekonomi berkontribusi besar terhadap menurunnya 
kualitas hidup caregiver karena tingginya biaya pengobatan pasien skizofrenia. Alejandra (2009) menegaskan bahwa perasaan terbebani dan ketegangan bagi caregiver yang dapat mengurangi kualitas hidup caregiver dan mengurangi kualitas perawatan terhadap anggota keluarganya yang menderita skizofrenia. Berdasarkan hasil uji bivariat antara faktor kualitas hidup caregiver dengan frekuensi kekambuhan pasien skizofrenia ditemikan hubungan yang sangat kuat dan memiliki arah hubungan negatif artinya semakin tinggi kualitas hidup keluarga sebagai caregiver, maka semakin berkurang frekuensi kekambuhan pasien skizofrenia. Hasil penelitian ini berbeda dengan penelitian Watson (2010) yang menemukan bahwa anggota keluarga yang merawat penderita skizofrenia tidak mengalami masalah pada semua dimensi yang diukur dan kualitas hidup anggota keluarga yang merawat penderita skizofrenia berada dalam tingkat sedang. Hal tersebut mungkin karena dinegara barat beban ekonomi tidak begitu dirasakan dan fasilitas kesehatan yang sangat memadai.

Intervensi yang dapat dilakukan oleh perawat jiwa untuk mempertahankan atau bahkanmeningkatkankualitashidup caregiver yaitu dengan meningkatkan kemampuan adaptasi caregiver dalam merawat pasien skizofrenia. Kemampuan menyeimbangkan antara emosi negatif dan emosi positif diperlukan agar domain psikologis dalam kualitas hidup dapat meningkat. Menurut Maria (2010) kesejahteraan psikologis (psychological well-being) adalah kondisi seseorang yang bukan hanya bebas dari tekanan atau masalah mental saja, melainkan memiliki kemampuan untuk menerima diri sendiri maupun kehidupan orang lain yang dalam hal ini adalah penderita skizofrenia (self-acceptance).

Selanjutnya, berkaitan dengan hasil uji multivariat menggunakan analisis regresi logistik dari keempat faktor dari caregiver didapatkan bahwa kualitas hidup yang paling dominan berhubungan dengan kekambuhan pasien skizofrenia. Temuan ini mengindikasikan bahwa kualitas hidup caregiver merupakan factor yang paling berhubungan dengan kekambuhan pasien skizofrenia dibanding faktor pengetahuan, dukungan dan kehidupan yang penuh stres. Implikasinya bagi tenaga kesehatan adalah bahwa dalam merawat pasien skizofrenia sebaiknya menggunakan pendekatan family centerd care, sehingga dalam merawat pasien, tidak hanya fokus pada pasien saja tetapi pada keluarga secara keseluruhan.

\section{Simpulan}

Pada penelitian ini dapat disimpulkan bahwa semua variabel independen (dukungan keluarga, pengetahuan keluarga, kualitas hidup, dan peristiwa hidup penuh stres memiliki hubungan dengan frekuensi kekambuhan pasien skizofrenia. Faktor dari caregiver yang paling dominan berhubungan dengan kekambuhan skizofrenia adalah kualitas hidup caregiver. Disarankan kepada tenaga kesehatan, khususnya perawat, agar dalam merawat pasien skizofrenia menggunakan pendekatan family centered care. Perawat memberikan pendidikan keperawatan terhadap keluarga dan masyarakat, mendirikan dan mendampingi paguyuban keluarga sebagai caregiver skizofrenia, mengimplementasikan caregiver support group, memperhatikan hak asasi caregiver dan pasien skizofrenia dengan membantu mempermudah akses mendapatkan obat, memberikan informasi tentang alur pengobatan, dan mendengarkan keluhan caregiver, serta aktif berkerjasama dengan Puskesmas.

\section{Daftar Pustaka}

Alejandra. (2009). Quality of life in caregivers of patients with schizophrenia: A literature review. Health and Quality of Life Outcomes, 7, 84. doi:10.1186/1477-7525-7-84.

Alsherif, Z.A.E.G., \& Elrahman, S.G.E.S. (2013). Schizophrenic patients's perception of factors leading to relapse. Journal of American Science, 9(12), 512-517. ISSN: 1545-1003. http://www.jofamericanscience. org. 68 .

Awad, A.G., \& Voruganti, L.N. (2010). The burden of schizophrenia on caregivers: A 
Laeli Farkhah : Faktor Caregiver dan Kekambuhan Klien Skizofrenia

review. Pharmacoeconomics, 26, 149-162.

Birley, J. L. T., \& Wing, J. K. (2007). Influence of family life on the course of schizophrenic disorders: a replication. British Journal of Psychiatry, 121, 241-258.

Buckley, P.F. (2006). Schizophrenia. Philadelphia: Elsevier.

Chan, K.W. 2015). Perceived risk of relapse and role of medication: Comparison between patients with psychosis and their caregivers. Social Psychiatry Psychiatr Epidemiol, 50, 307-315.doi: 10.1007/s00127-014-0930-0.

Chorwe-Sungani, G., Namelo, M., Chiona, V., \& Nyirongo, D. (2015). The views of family members about nursing care of psychiatric patients admitted at a mental hospital in Malawi. Open Journal of Nursing. 5, 181-188. http://dx.doi.org/10.4236/ojn.2015.53022.

Christy, L.M. (2011). Relapse in skizofrenia. Chief Research Officer, Jockey Club Early Psychosis (JCEP) Project, Department of Psychiatry. The University of Hong Kong, 16(5).

Epstein-Lubow, G., Gaudiano, B.A., Hinckley, M., Salloway, S., \& Miller, I.W. (2010). Evidence for the validity of the American Medical Association's caregiver self-assessment questionnaire as a screening measure for depression. Journal of the American Geriatrics Society, 58(2), 387-388.

Espina, A., \& Gonzalez, P. (2003). Intervenciones familiares en la esquizofrenia. Cambios en la sintomatologia y el ajuste social. Revista Salud Mental, 26, 51-58.

Felicia, G. (2012). Self-assessment of functional ability in schizophrenia: Milestone achievement and its relationship to accuracy of self-evaluation. Psychiatry Research. doi: 10.1016/j.psychres.2013.02.035.

Fisher, J. E. M. (2011). The therapeutic role of the mental health nurse: implications for the practice of psychological therapies. Thesis. Southern Cross University, Lismore, NSW.
Friedman, M. M. (2010). Buku ajar keperawatan keluarga: riset, teori, dan praktik/Marlindan M. Friedman, Vicky R. Bowden, Elaine G Jones; alih bahasa, Achir Yani S. Hamid., et.al; editor edisi bahasa indonesia, Estu Tiar, Ed. 5. Jakarta: EGC.

Guiterrez-Maldonado, J., Caqueo-Urizar, A., Kavanagh, D.J. (2006). Burden of care and general health in families of patients with schizophrenia. Soc Psychiatry Psychiatr Epidemiol. 40(11):899-904.

Hemels \& Schreiner. (2013). Definitions and drivers of relapse in patients with schizophrenia: A systematic literature review. doi: 10.1186/1744-859X-12-32.

Ingkikiriwang. (2010). Hubungan antara dukungan keluarga dengan keberfungsian sosial pada pasien skizofrenia pasca perawatan di rumah sakit (Tesis). Fakultas Psikologi, Universitas Diponegoro, Semarang.

Keliat, B.A. (2006). Proses keperawatan jiwa. Jakarta: EGC.

Maria, C. (2010). Schizophrenia and quality of life: How important are symptoms and functioning?. International Journal Mental Health. doi: 10.1186/1752-4458-4-31.

Mubarak, A.R., \& Barber, J.G. (2013). Emotional expressiveness and the quality of life of patients with schizophrenia. Soc Psychiatry Psychiatr Epidemiol, 38(7), 3804.

Pratama, Syahrial, \& Isak. (2015). Hubungan keluarga pasien terhadap kekambuhan skizofrenia di BLUD RSJ Aceh. Jurnal kedokteran syiah kuala, 15(2).

Porsdal, V., Beal, C., Kleivenes, O.K., Martinsen, E.W., Lindstrom, E., \& Nilsson,H. (2010). The scandinavian solutions for wellness study-atwo-arm observational study on the effectiveness of lifestyle intervention onsubjective well-being and weight among persons with psychiatric disorders. $B M C$ Psychiatry, 10(42). doi: 10.1186/14711244x-1110-1142. 
Laeli Farkhah : Faktor Caregiver dan Kekambuhan Klien Skizofrenia

Rafiah, I., \& Sutharangsee, W. (2011). Review: Burden on family caregivers caring for patients with schizophrenia and its related factors. Nurse Media Journal of Nursing, 1(1), 29-41.

Sachit, K.R., \& Al-Jubbori, A.K. (2013). Impact of caregivers' expressed emotion upon schizophrenic patient relapsing. Kufa Journal for Nursing Science, 3(1).

Sariah, A.E., Outwater, A.H., \& Malima, K.I. (2014). Risk and protective factors for relapse among individuals with schizophrenia: A qualitative study in Dares Salaam, Tanzania. BMC Psychiatry, 14, 240. doi:10.1186/ s12888-014-0240-9.

Siregar, C. (2006). Farmasi klinik teori dan penerapan. Jakarta: EGC.

Watson, R. (2010). Handbook of disease burdens and quality of life measures. ISBN: 978-0-387-78664-3.

Weret, Z.S., \& Mukherjee, R. (2014). Prevalence of relapse and associated factors in patient with schizophrenia at Amanuel Mental Specialized Hospital, Addis Ababa, Ethiopia: institution based cross sectional study. International Journal of Interdisciplinary and Multidisciplinary Studies (IJIMS), 2(1), 184-192. 184. ISSN: 2348-0343.

WHO. (2014). Schizophrenia. Retrieved from http://www.who.int/mediacentre/factsheets/ fs397/en/. 